\title{
Analysis of the Efficiency Technology Transfer Offices in Management: The Case of Spain and Kazakhstan
}

\author{
Anel A. KIREYEVA ${ }^{1}$, Sharbanu TURDALINA ${ }^{2}$, Dinara MUSSABALINA ${ }^{3}$, \\ Nadira M. TURLYBEKOVA ${ }^{4}$, Zauresh B. AKHMETOVA ${ }^{5}$
}

Received: June 02, 2020 Revised: June 28, 2020 Accepted: July 12, 2020

\begin{abstract}
This research is defined as a study regarding on structured and systematized of existing literature review of the intersection between intellectual property management, management and technology transfer offices (TTOs). It takes a deeper look at requirements within universities, scientific institutions and the business environment should be interconnected with each other. The literature review shows that TTOs have control over the process of knowledge transfer and they have contributed to improving the efficiency of the use of production and human resources. In this paper, authors proposed the methodological tools based on methodology model, which identified success factors for using project management in TTO between two countries - Kazakhstan and Spain. Further, we used methodology is focused on solving the problems of quantitative analysis based on the use of primary data, which allowed us to reach a huge number of respondents without any restrictions, and secondary data from statistical database. Findings and results are summarized at the end of article show that Kazakhstan is following the path of the Spanish experience. However, Kazakhstan can become more successful in commercializing scientific technologies and transferring knowledge and technologies. In turn, Spain can use the data from our analysis to work on barriers and improve the activities of TTOs.
\end{abstract}

Keywords: Economics, Innovation, Business, Technology Transfer Office, Management, Intellectual Property

JEL Classification Code: G32, O32, O34

\section{Introduction}

Today developed countries that are actively developing due to important components are science, research and scientific

${ }^{1}$ First Author and Corresponding Author. Chief Researcher, Al-Farabi Kazakh National University, Institute of Economics of the Ministry of Education and Science of the Republic of Kazakhstan [Postal Address: 29 Kurmangazy Street, Almaty, 050010, Kazakhstan] E-mail: kireyeva.anel@ieconom.kz

${ }^{2} \mathrm{PhD}$ Student, Higher School of Economics and Business, Al-Farabi Kazakh National University, Kazakhstan.

E-mail: shturdalina@gmail.com

${ }^{3} \mathrm{PhD}$ Student, L. N. Gumilyov Eurasian National University, Kazakhstan. E-mail: d.mussabalina@gmail.com

${ }^{4}$ Associate Professor, Higher School of Economics and Business, Al-Farabi Kazakh National University, Kazakhstan.

${ }^{5}$ Higher School of Economics and Business, Al-Farabi Kazakh National University, Kazakhstan

() Copyright: The Author(s)

This is an Open Access article distributed under the terms of the Creative Commons Attribution Non-Commercial License (http://Creativecommons.org/licenses/by-nc/4.0/) which permits unrestricted noncommercial use, distribution, and reproduction in any medium, provided the original work is properly cited. institutions. Intellectual property management creates its own problems and difficulties. Digital technologies, on the one hand, contribute to the acceleration of economic and scientific-technical development of the human community, and on the other hand, serve as a tool for increasing competition and competition between them. In the context of the information revolution, globalization is synonymous with the interpenetration and merging of economies under the pressure of increasingly intense competition and the acceleration of scientific and technological progress as the world moves towards digital solutions to most problems, the sphere of intellectual property management systems is developing.

The main motivation for any research and development activities carried out at the national and international levels is to create more data and contribute to the development of the economy. This can be achieved through interaction or collaboration between the business world and academia. Technology transfer offices (TTOs) are created to develop such cooperation. TTO development is a growing area of 
both academic research and practice (Aldridge \& Audretsch, 2010; Huyghe \& Knockaert, 2015). For example, American universities have started to create TTO to support the commercialization of research (Bertha, 1996). This trend has spread internationally and caused the success of many American universities.

In developed countries, such centers established with EU funds. In developing countries, such as Kazakhstan, these centers haven't yet been formed, but there are prerequisites for their formation and development. However, many countries have an important problem is the further development of TTO, as foreign experience shows the need for these centers, on the one hand, and the question of their future funding, on the other.

Thus, universities, scientific institutions and the business environment should be in close interconnection with each other. This process is the integration of education, science and business, or the search for talent, the exchange of information and students, the commercialization of scientific results. The environment involved in this process is called TTO (Bigliardi, Galati, Marolla, \& Verbano, 2015), which are part of universities or research institutes.

The exchange of experience and information becomes the main way to solve many problems. One such example is the project management knowledge base. This science is a squeeze of the best ways and methods to implement new ideas. Still, one of the first users and teachers are universities and related organizations. It is for universities that a special methodology is created for project management, as well as for all other areas of activity (Trilling \& Ginevri, 2017). This document shows the relationship of project management with the educational process.

Looking on the above, it is clear that TTOs have control over the process of knowledge transfer and is crucial for the application of research results. Further, our study will discuss the issue of studying the essence of TTO as an auxiliary tool.

One of the fundamental reasons for funding research at universities is that it will be profitable. However, the effectiveness of universities 'use of relevant research results may be significantly questioned. We believe that universities, research institutes and TTO should use a strategic approach when dealing with issues of obtaining commercial value. Thus, the main goal of TTO is to help research products reach their commercial potential.

Generally, in this scientific research, we tried to study the experience of developed and developing countries. We decided to conduct a comparative analysis of two countries - Kazakhstan and Spain. Since they had similar starting conditions at the beginning of commercialization of scientific research. The approach of the selected European country, i.e. Spain, which is one of the countries that built research centers and worked independently in connection with existing support, the criteria for software solutions can be evaluated along with the context and funding opportunities.

The chosen topic wasn't considered as an independent scientific research. Despite the existence of many studies on this issue, this study currently remains poorly studied. The relevant theoretical framework is discussed in section 2 . The methodology of this approach is discussed in section 3: the research area and sources, data extraction processes, and source data used for the survey of research activities. Section 4 presents the results obtained from the analysis. Section 5 provides the authors' considerations conclude the article.

\section{Literature Review}

The main goal of TTOs is to help any research product reach its potential and focus on intellectual performance. The development of new companies and licensing of intellectual content are seen as the main ways to commercialize research. The scientific literature related to TTO generally deals with licensing and patenting, while spin-offs are becoming ways that are more significant in which commercialization can be achieved (Bertha, 1996; Siegel \& Wright, 2007). However, TTOs play an important role in the learning process, and these universities can be developed in order to systematize, create, accumulate and disseminate academic knowledge so that new users can use it in practice (Aldridge \& Audretsch, 2010; Huyghe \& Knockaert, 2015). Further, Caldera and Debande noted that the transfer of knowledge between the university, the science institute and TTO would have better performance by the interconnected nature of the work (Caldera \& Debande, 2010). In another scientific study, it was shown that technology transfer refers to the transfer of scientific and technical knowledge and experience for the provision of scientific and technical services, the application of technological processes and the production of products (Kireyeva, Abilkayir, \& Tsoy, 2018). However, there are also differences, which are that some authors understand the process of technology transfer as the transfer of information about innovation up to its commercialization, that is, directly link this process to the mandatory extraction of profit, while others believe that the transfer of technology does not necessarily entail profit (mainly this applies to environmental technologies).

Traditionally, there are three main groups of technologies: production process technologies (process technologies), product technologies (product technologies) and management technologies (management technologies). They can be supplemented by resource-saving technologies, consumption technologies, information and other technologies that are becoming increasingly important in the modern world. Technology transfer ensures the interconnection of science and production, with a special place being taken by technology transfer offices as part of state scientific and 
educational organizations (Graff, Heiman, \& Zilberman, 2002). A variety of names - technology transfer centers (offices), licensing or patenting offices (departments), etc. Their main function is to provide participants in innovation processes with all the necessary services to realize their potential and develop innovative opportunities.

By identifying three types of TTO with different aims and different models. It is need to highlight, the first group spinoffs enjoy active involvement from TTOs (Berbegal, Ribeiro, \& Sánchez, 2015). In these spin-offs, academic entrepreneurs work closely with TTOs, receiving personalized assistance during technological development, business start-up, and the initial stages of business operations. The second group spinoffs operate under license agreements. In the third group, TTO or university holds equity in the spin-off. By holding a financial stake in the spin-off, the university bears a risk. Our empirical study also compares TTO types in Kazakhstan and Spain. In Spain,TTOs work on the principle of the first type, receiving support from the initiation of projects to the implementation of spin-off companies. However, Kazakhstan's TTOs still work with license agreements and patents, which is the second type. This is a big gap: Kazakhstan's science does not reach the implementation of scientific results in the real sector of the economy.

In several studies, the authors described the commercialization of their inventions. Some researchers believe that work experience, publications, and attitudes to open science related to patenting behavior (Huang, Feeney \& Welch, 2011). At the time, Lawson described that researchers with public funding are more likely to get patents compared to researchers with private funding (Lawson, 2013). Other researchers believe that the distribution of fees between the inventor and the department is an important factor for increasing patent activity in universities (Baldini, 2010).

Some scholars note that it is important to use a fairly simplified perspective when describing how the integration of education, science, and business is managed by different types of universities (Potluri, Lee, Khan, \& Vali, 2012; Phillips, Nestor, Beach \& Heitman, 2018). For example, scientific institutions play a leading role at the national level. Universities play an important role in building a business, without negative impacts (environmental, economic, etc.) on society (Bigliardi, Galati, Marolla, \& Verbano, 2015).

Many developed countries, such as the EU, the US, and the Republic of Korea, are focusing on other actions. For example, TTOs in these countries used to improve results, such as introducing hours for consulting, focusing more on the growth of the researcher, creating a patent culture, shifting the focus from basic to applied research, and proper policies in the integration of education, science and business (Chen \& Kenney, 2007). As a result, in these countries, the following factors have influenced the development of TTOs: the increasing role of intellectual, information, organizational, and managerial resources; the consideration of the human being as the main, determining and inexhaustible factor of economic growth.

European TTOs suggest that universities should attract outstanding researchers, professional staff, provide material and financial resources, and develop it infrastructures that facilitate cooperation between universities and industry (Algieri, Aquinom, \& Succurro, 2011). Further, other researchers show a positive relationship between the speed of innovation and the success of TTOs in the US (Allan, Kistler, Lowe, Dunn, McGowan, \& Whitcher, 2008; Aldridge \& Audretsch, 2010; Huyghe \& Knockaert, 2015). This is in terms of revenue from licensing and creating new businesses. Since the United States is a pioneer of integration of education, science and business. The resources and competence of the TTO, in turn, influence the speed of innovation, as they speed up the process of matching inventive inventions and industrial commercialization.

The most interesting thing is that in China, the government requires foreign firms to conduct research in order to learn from their experience. Therefore, Chinese private sector firms were able to "absorb" the advanced technologies of foreign firms. This feature of the international transfer of management technologies is one of the key problems.

Lindner and Wald proposed an interesting solution to address the issue of knowledge management and transfer. They created a model for organizing an integration project (Lindner \& Wald, 2011). Innovation cannot flourish without reliable integration management systems. According to the system proposed by Lindner and Wald, the project management process is divided into a list of criteria that can then be measured. These are, in fact, success factors that help ensure the creation of decent management practices.

The concept of sustainability is also much studied in project management. Sustainable project management is considered in the works (Sabini, Muzio, \& Alderman, 2019; Aarseth, Ahola, Aaltonen, Økland, \& Andersen, 2016). This area remains fragmented, undermining sustainable and consistent development.

Implementing innovative products through project management is one of the new topics in project management. Successful introduction of new products to the market is the lifeblood of most organizations. Nevertheless, it is a complex and difficult task, of the total products presented, almost $90 \%$ have not reached their business goals. It is difficult to predict why some new products are successful and most are not. Knowledge management, where learning based on projects, faces many challenges (Bresnen, Edelman, Newell, Scarbrough, \& Swan, 2003; Kireyeva, Lakhonin, \& Kalymbekova, 2019; Lee \& Xuan, 2019). Because the projects differ significantly from each other. In project management, Kamara has developed a structure that is related to the business structure in universities (Kamara, 
Anumbab, \& Carrillob, 2002). The focus is on business drivers for practical understanding of the knowledge used in the research.

Project management and innovation are similar. Since the project itself has a new idea or innovative ideas. In project management research, there is a tendency to equate a project with an innovative organization (Lenfle, 2008). This link between projects and innovation has been established through research on key factors of innovation success. In innovative organizations, there is an excessive focus on project execution and management methods, planning, scheduling, cost control, etc. However, many studies don't mention project management as a tool for highlighting innovation.

Balachandra and Friar identified project management factors that can indicate the success or failure of $R \& D$ projects and the introduction of new products (Balachandra \& Friar, 1997). Since the list of factors is very long, they stopped at the main ones. The project management factors such as the role of the project manager, quality management, risk management, and stakeholder management were identified. In other studies use project management tools in universities such as enterprise resource planning system (Shakkah, Alaqeel, Alfageeh, \& Budiarto, 2016).

Certain scientists highlighted the fact is that universities may have few research results worth commercializing, particularly due to the embryonic nature of the technology, which may require significant further modifications (Marozau \& Guerrero, 2016; Belitski, Aginskaja, \& Marozau, 2019). Thus, real problems for TTOs in Kazakhstan in the context of the post-soviet are faced with a high level of university bureaucracy and lack of economic motivation among employees. In addition, TTOs for the commercialization of inventions have a lack of financial resources for independent marketing of technologies, lack of freedom in decisionmaking on obtaining a patent, lack of participation of industry and networks. Many areas have explored to solve these problems, and there are proposals for real integration (Sabden, 2018).

According to the literature review, it should be concluded that the properties of TTOs as structures are the determining factors in choosing the form of transfer of management technologies. In addition, the transfer of advanced management methods contributes to improving the efficiency of the use of production and human resources, contributes to the growth of the competitiveness of national producers, which is becoming especially relevant in the globalized world economy. In Kazakhstan, as in many the CIS countries, there is a clear contradiction between relatively advanced production technologies that can be obtained through international scientific, technical and industrial exchange (ii.e. existence backward management technologies). This contradiction is caused by a number of factors, but first of all by the historically established and dominant administrative and command management system after soviet-union reforms.

Generally, we found differences in contingent preferences for ways to commercialize. In addition to patenting, licensing, and commercialization, TTOs sometimes use different ways to transfer technology around the world. Thus, we found out that TTO management technologies have the following features:

(1) Scientific and technical achievements are unique. They cannot be commercialized by themselves (as is the case with goods in material production).

(2) The acquisition of scientific knowledge and especially its materialization in new technology is characterized by a high degree of uncertainty, technical and economic risk.

(3) Creating innovative products using intellectual property management is one of the new topics in management. This feature of scientific and technical knowledge and management technologies reflects their property as public goods, namely the property of non-competition in consumption.

(4) Management technologies in TTO, as well as scientific and technical knowledge, tend to "absorb" advanced technologies of foreign firms, as in China.

It should be taken into account that in Kazakhstan there is a clear contradiction between relatively advanced production technologies that can be obtained through international exchange, and existing backward management technologies. A number of factors, but first - the historically established and dominant for many decades administrative and command management system, causes this contradiction. Based on this assumption, we decided that the initial diagnostic algorithm should be based on methodological assessments, which have a quantitative basis by assessing of the efficiency TTOs in Management. This study is one of the scientific papers that analyze the state of project management, compare developed and developing countries (Spain and Kazakhstan) on the use of scientific results in the real economy, as well as to identify positive aspects and barriers.

In this regard, the problems of transfer of advanced management technologies, their implementation in practice and their significance for the host economy are becoming more and more theoretical and practical understanding in the modern scientific literature. We discussed the peer-reviewed literature in the field of the project management, research organizations and their regulation in the light of numerous recent publications on a variety of strategies used by many in practice. In addition, we are trying to make a small scientific contribution, but a growing stream of literature that constructively criticizes the current view of TTO and how to 
manage and use them in the process of integration. All this once again confirms the relevance of this scientific research.

\section{Research Methods}

The methodological basis of this research was the achievements of world and domestic economic science, other related branches of scientific knowledge, the results of scientific and practical publications and expert surveys on the development of TTO. We used a systematic approach to research the state of technology from the point of view in the field of patenting and management, as well as an academic view of how TTO should be managed. This study was conducted based on a systematic approach that is very often used in our research (Satpayeva, Kireyeva, Kenzhegulova, \& Yermekbayeva, 2020). In addition, the methodological approach will be based on a set of systematic reviews of scientific articles from three main databases: Emerald Insight, Web of Science and Scopus. All literature in the field of business Economics research in databases was searched for transfer technology offices ("technology transfer center") or incubator ("science park") and management project. To find the connection between universities, science and business it will be need to find a set of indicators that will be related to dimension activities TTOs in Kazakhstan and Span.

In this study, we decided to conduct a comparative analysis of two countries - Kazakhstan and Spain. Since they had similar starting conditions at the beginning of commercialization of scientific research. The approach of the selected European country, i.e. Spain, which is one of the countries that built research centers and worked independently in connection with existing support, the criteria for software solutions can be evaluated along with the context and funding opportunities. The technological science of Spain was influenced by the American scientific and inventive environment, which is also influenced by the post-soviet system in Kazakhstan. In addition, the Polytechnic University of Valencia with their TTOs (IDEAS UPV) and spin-off companies selected from it agreed to conduct a survey.

Because of the search, we offer preliminary analysis in several stages:

(1) General economic picture. Before showing the results of an empirical study of the integration process in Spain and Kazakhstan, they decided to compare the overall economic picture (John, Khan, Raeside, \& White, 2007; Saunders, Lewis, \& Thornhill, 2009). To compare the integration process of education, science and business of two countries: Spain and Kazakhstan, we turned to the information site of the World Economic Forum, which every year conducts an analytical report on countries around the world. The report is divided into pillars, of which we selected the 12th about innovations, because: first, it is during the creation of innovations that the data work together three areas, this can be seen by the names of the columns.

(2) Empirical part of the study. In the empirical part, we developed a model for an integration project, based on the work (Lindner \& Wald, 2011). In this model, factors were identified for project management that affect the integration process. Lindner's work is intended to transfer knowledge, in our case it is the transfer of knowledge, scientific results and technology in general. Few changes have been made to the Lindner model, we have combined the ICT system and the project management culture, since the ICT system is a project management tool and is used through the project management culture. Without a culture of communication, for example, it is difficult to understand a person not from the project environment. We also added the resource factor, which is divided into financial, human and infrastructure. All of these types of resources are managed in project management (Trilling \& Ginevri, 2017). The study was conducted through interviews and after they distributed a pre-prepared questionnaire, where there were statements on the Likert scale.

Features of the proposed methodology contains a comprehensive system of characteristics indicators. Based on international differences in the integration of universities with businesses, we use the Likert scale method. We integrate the hypothesis about factors of organization and structure, resources, ICT systems and culture into a model aimed at explaining the effectiveness of TTO. The figure 1 measurement methodology model differs from other models in that it aims to identify success factors for using project management in TTO (see Figure 1).

The proposed methodology contains a complex system of characteristics indicators. The measurement methodology model offers to measure the success factors of scientific project implementations. Thus, to develop the research model, we rely on the work (Lindner \& Wald, 2011) and other studies described above. We put all the formal processes and structures of TTO to the category "Organization and processes" and "Resources". Further, "ICT systems" include all systems to support TTO processes. The third category of factors covers informal aspects, such as organization culture, informal communication, leadership, and social capital. These categories correspond to general research on technology transfer. We assumed that factors directly affect the success of commercialization of scientific projects, as well as the interdependence between factors that exist. Our 


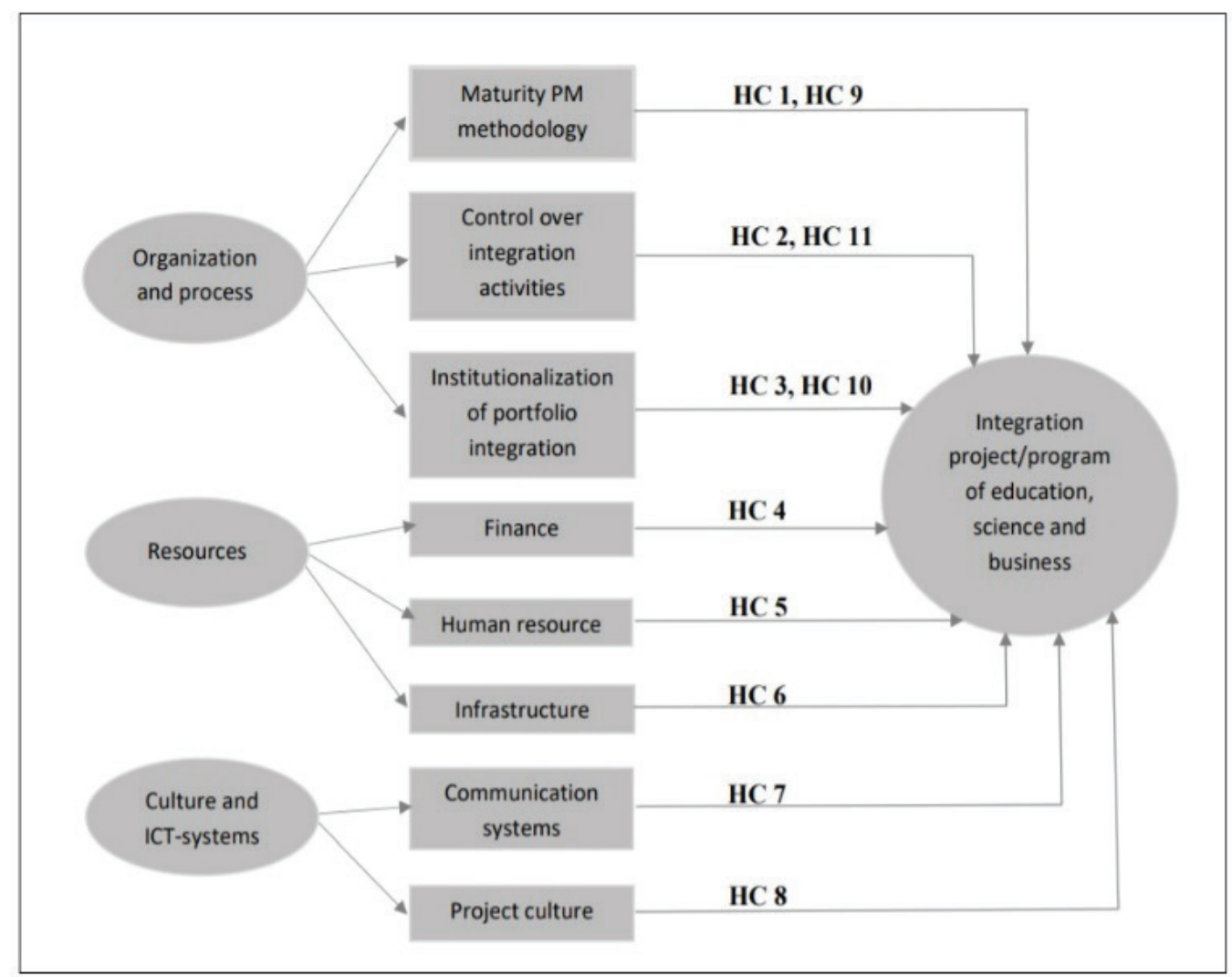

Figure 1: Methodology model, which identified success factors for using project management in TTO

model aims to explain the effectiveness of TTO management as a dependent variable. TTO efficiency is the perceived adequacy of generating, storing, searching, and transferring research to the business domain.

Below is a questionnaire that we used to conduct an online survey, which allowed us to reach a huge number of respondents without any restrictions, which related to the location of participants (see Table 1).

The survey respondents were top managers of spin-off companies, project managers integrating universities with a business structure, as well as organizers of the integration process between the scientific and business spheres of Kazakhstan and Spain.

Hypotheses statement - in this study, we assumed that factors directly affect the success of commercialization of scientific projects, as well as the interdependence between factors that exist. We analyzed and evaluated indicators with using the Likert scale. Each hypothesis corresponds to a score from 1 (absolutely wrong) to 5 (absolutely true), etc. (Vonglao, 2017). The data obtained are grouped by factors. Top managers of three integrated parties attended the survey: professors and researchers working with research projects on commercialization in universities; certified PM managers who train and advise private firms and companies (integrate); private organizations that conduct research, are engaged in the introduction of their developments on the market. The survey participants were selected by careful selection: which should be related to the integration of science, education and the business environment.

For the survey, a manager was selected based on the convenience approach. The questionnaire was filled an online survey and out via e-mail. It should be noted here that managers chose this method as the most convenient option. If feedback is needed, then the most effective way is face-toface interview (John, Khan, Raeside, \& White, 2007).

We analyzed the results of the survey using our model. The analysis involved 21 managers from Spain and 43 managers from Kazakhstan. To obtain the average number, the following formula of arithmetic mean value was used. In particular, when statistical processing of economic indicators $X=(x 1, x 2, \ldots, x n)$ is most often used, the arithmetic mean value of the partial indicators $x i$ : 
Table 1: Sample - Basic survey of questioner

\begin{tabular}{|c|c|c|c|c|c|c|}
\hline No. & Statement & 1 & 2 & 3 & 4 & 5 \\
\hline HC 1 & $\begin{array}{l}\text { Scientific work passes } \\
\text { only through projects. }\end{array}$ & & & & & \\
\hline $\mathrm{HC} 2$ & $\begin{array}{l}\text { There are projects } \\
\text { integrated with business } \\
\text { implemented in } \\
\text { companies. }\end{array}$ & & & & & \\
\hline $\mathrm{HC} 3$ & $\begin{array}{l}\text { The number of } \\
\text { scientific projects in the } \\
\text { organization is more than } \\
\text { five. }\end{array}$ & & & & & \\
\hline $\mathrm{HC} 4$ & $\begin{array}{l}\text { All projects are funded by } \\
\text { private companies. }\end{array}$ & & & & & \\
\hline HC 5 & $\begin{array}{l}\text { Undergraduates and } \\
\text { doctoral students are } \\
\text { involved in projects. }\end{array}$ & & & & & \\
\hline HC 6 & $\begin{array}{l}\text { There is support from the } \\
\text { state for the integration } \\
\text { of universities and } \\
\text { companies. }\end{array}$ & & & & & \\
\hline $\mathrm{HC} 7$ & $\begin{array}{l}\text { The organization has } \\
\text { a common information } \\
\text { system. }\end{array}$ & & & & & \\
\hline $\mathrm{HC} 8$ & $\begin{array}{l}\text { Project management } \\
\text { standards are used in } \\
\text { scientific projects. }\end{array}$ & & & & & \\
\hline $\mathrm{HC} 9$ & $\begin{array}{l}\text { The rules for selecting } \\
\text { projects are clear and fair. }\end{array}$ & & & & & \\
\hline HC 10 & $\begin{array}{l}\text { There is a difference } \\
\text { between integration and } \\
\text { conventional projects. }\end{array}$ & & & & & \\
\hline HC 11 & $\begin{array}{l}\text { Project reporting is } \\
\text { prepared for the Ministry } \\
\text { of Education and Science } \\
\text { of the Republic of } \\
\text { Kazakhstan, the university } \\
\text { administration. }\end{array}$ & & & & & \\
\hline
\end{tabular}

$$
x=\frac{1}{n} \sum_{i=1}^{n} x 1=\frac{1}{n}(x 1+\ldots+x n)
$$

where:

$\mathrm{X}$ - the arithmetic mean value of partial indicators

$\mathrm{n}$ - the number of partial indicators in the sample

$\mathrm{x} 1, \mathrm{x} 2, \mathrm{xn}-$ the geometric mean of several positive real numbers, is a number that can be replaced by each of these numbers so that their product does not change.
Generally, the proposed methodology is focused on solving the problems of quantitative analysis based on the use of primary and secondary data. The information received will allow to get complete, reliable and timely information about current processes related to the use of TTO.

It should be concluded that the proposed methodological tools offer a model for organizing an integration project. Thus, the developed methodological tools will allow to conduct a reliable and formalized analysis in order to get a real picture in Kazakhstan and Spain.

\section{Analysis and Results}

The experience of many countries shows the need for state financial support for TTO, especially in countries where research organizations are mainly state-owned, such as developing countries such as Kazakhstan, Russia, Belarus, etc. During analyzing of the literature review in the field of the management experience in the field of TTO, we decided to focuses on those countries that have not only achieved significant results in the implementation of scientific and technical achievements, but also had the opportunity to obtain reliable and formalized data. Generally, we have implemented a systematic (integrated) approach in our work. This approach allows us to develop a structure that corresponds to the tasks of universities for technology transfer, with the need to analyze the role of the resulting TTO configuration.

Further, the comparative analysis of innovations in Spain and Kazakhstan is shown separately in Figure 2.

It is should be noted that innovation is in last place among other indicators in both countries. Figure 2 shows the difference between the innovative indicators in Spain and Kazakhstan. We chose indicators such as innovative ability, quality of scientific results and the company's costs of research and development differ greatly. Thus, there is a big gap between European and Central Asian in innovations. Similarly, the indicators of the two countries as state purchases of advanced technological products, and the presence of scientists and engineers are nearby. Kazakhstan's indicators show a big step for innovation, acquiring technological products on a par with Spain. This circumstance is a good prerequisite for working to eliminate existing internal and external barriers to the new conditions for organizing research based on technology transfer. Cooperation between universities and industry in the field of R\&D, patent applications diverge, as evidenced by an analysis of the process of integration of universities with business. This will be described in detail in the next section.

We analyzed the results of the survey using our model. The analysis involved 21 managers from Spain and 43 managers from Kazakhstan. The results presented in Figure 3. 


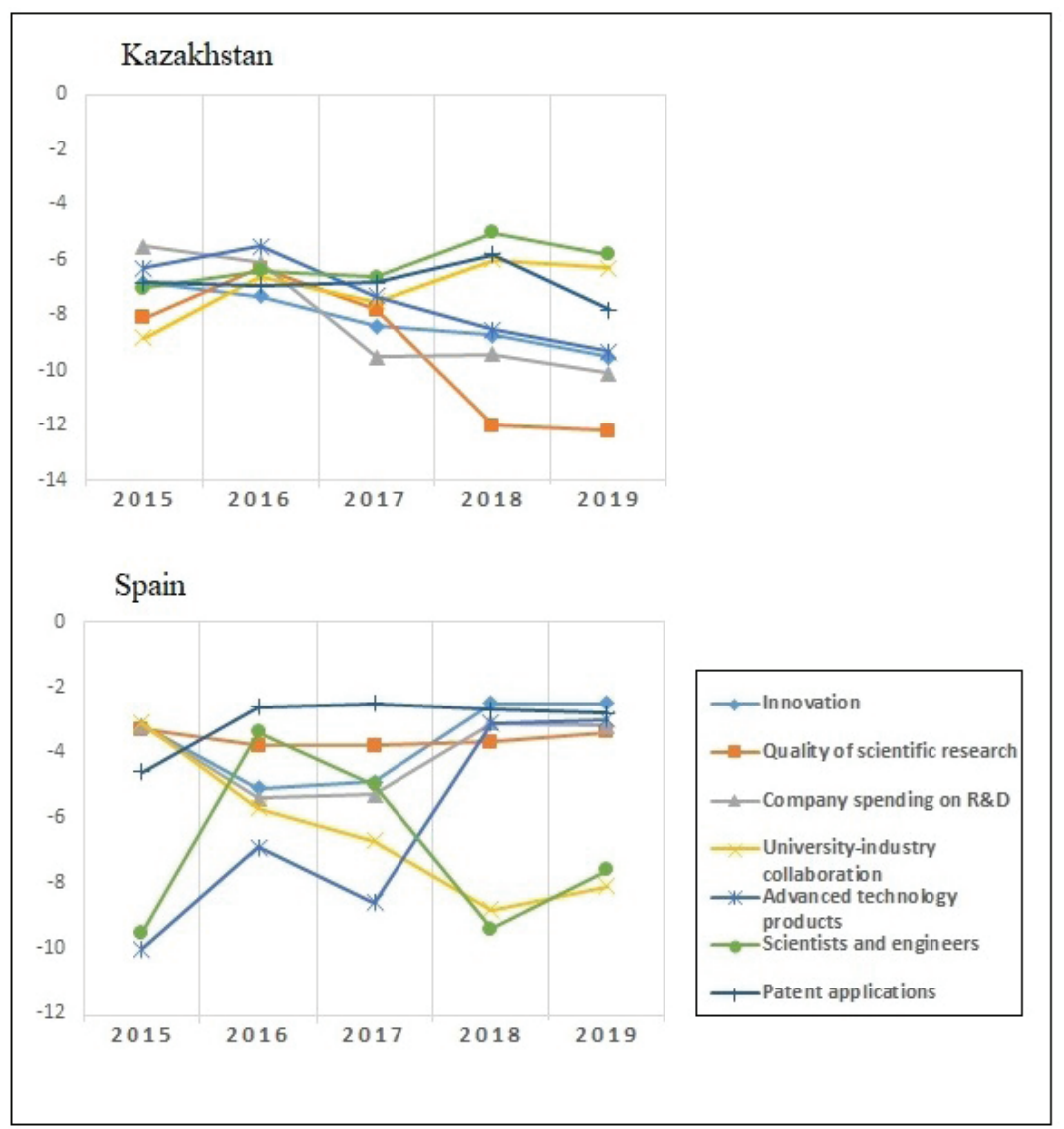

Figure 2: Comparative analysis of innovations in Kazakhstan and Spain, 2015-2019

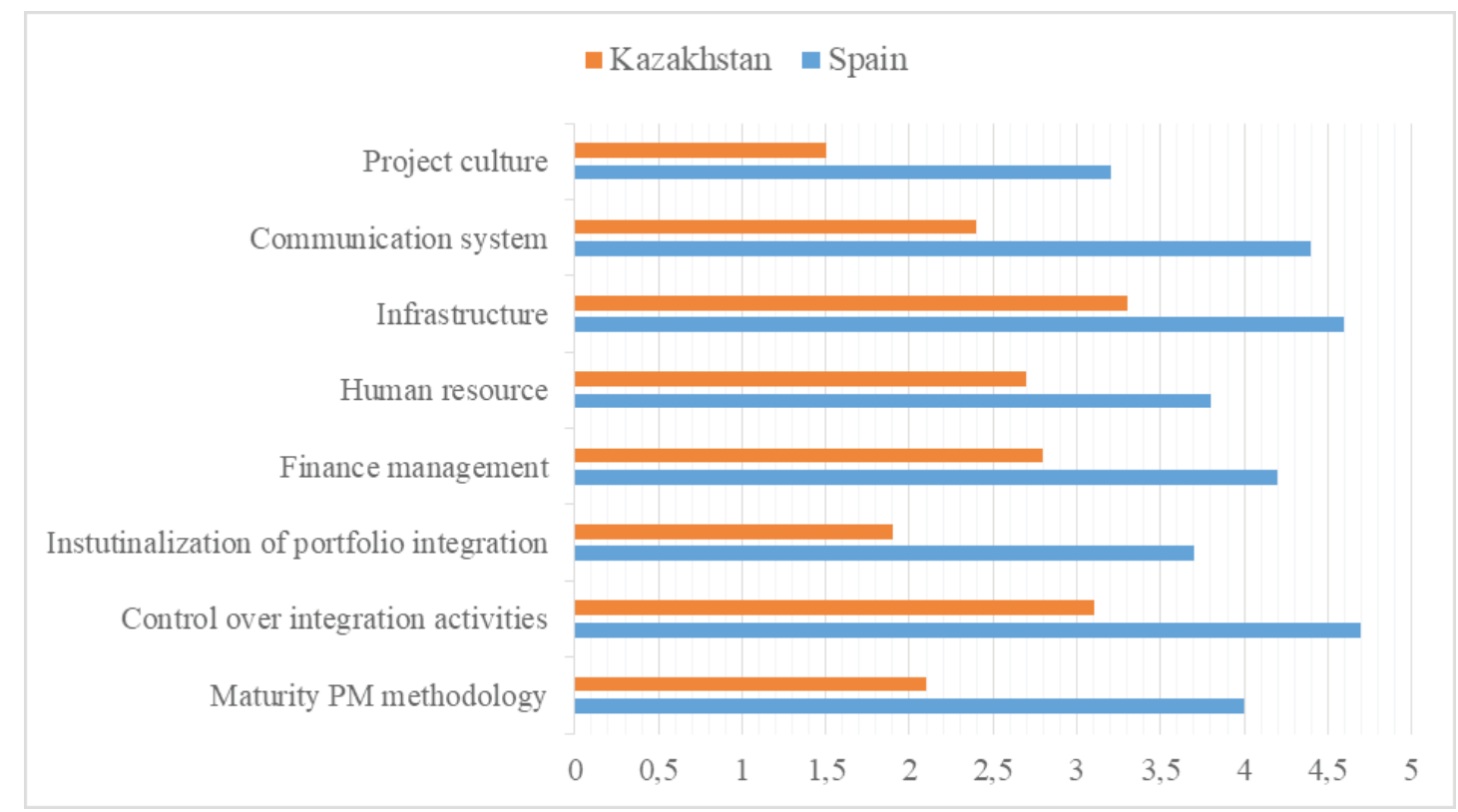

Figure 3: The obtained results of the basic survey 
Generally, the results a study of two countries on selected indicators are presented. The results of the study include the responses of participants in the integration process survey, which are ranked by the model and formula presented by us. The results for factors and hypotheses are described below.

As we described earlier, the data obtained are grouped by factors. Table 2 shows the results of survey in Spain (see Table 2).

It should be noted that the high figure is that of control over integration activities. It can be highlighted that the success of the Spanish TTOs is in the continuous monitoring of the integration process itself to the end of the chain. Nevertheless, the project culture for all its requirements has not yet been included. By improving this indicator, you can speed up and optimize the process. Table 3 shows the results of survey in Kazakhstan (see Table 3).

According to the presented data, it is clear that infrastructure is a high indicator, which is the most encouraging indicator for managers of Kazakhstan's TTO. Moreover, the lowest indicator of project culture is the same

Table 2: The obtained results of survey in Spain

\begin{tabular}{|l|c|c|c|c|}
\hline \multicolumn{1}{|c|}{ Spain } & \#1 & \#2 & \#3.. & Average \\
\hline Maturity PM methodology & 5 & 3 & 4 & 4,04 \\
\hline $\begin{array}{l}\text { Control over integration } \\
\text { activities }\end{array}$ & 5 & 5 & 5 & 4,71 \\
\hline $\begin{array}{l}\text { Institualization of portfolio } \\
\text { integration }\end{array}$ & 3 & 4 & 4 & 3,71 \\
\hline Finance management & 5 & 5 & 5 & 4,19 \\
\hline Human resource & 4 & 4 & 3 & 3,81 \\
\hline Infrastructure & 5 & 5 & 5 & 4,66 \\
\hline Communication system & 5 & 5 & 5 & 4,43 \\
\hline Project culture & 3 & 3 & 3 & 3,24 \\
\hline
\end{tabular}

Table 3: The obtained results of survey in Kazakhstan

\begin{tabular}{|l|c|c|c|c|}
\hline \multicolumn{1}{|c|}{ Spain } & \#1 & \#2 & \#3.. & Average \\
\hline Maturity PM methodology & 2 & 3 & 3 & 3,12 \\
\hline $\begin{array}{l}\text { Control over integration } \\
\text { activities }\end{array}$ & 2 & 2 & 2 & 1,93 \\
\hline $\begin{array}{l}\text { Institualization of portfolio } \\
\text { integration }\end{array}$ & 3 & 2 & 2 & 2,81 \\
\hline Finance management & 2 & 2 & 2 & 2,72 \\
\hline Human resource & 3 & 3 & 3 & 3,32 \\
\hline Infrastructure & 2 & 2 & 2 & 2,42 \\
\hline Communication system & 1 & 1 & 1 & 1,51 \\
\hline Project culture & 2 & 3 & 3 & 3,12 \\
\hline
\end{tabular}

as for Spain. Although the digital values are much lower. This proves that project managers in both countries are not yet successful users of project management tools.

We studied the efficiency of maintenance in Kazakhstan and Spain using the model of integration project organizations, which we have sharpened for analysis. The model includes the main factors such as organization and process, resources, culture and ICT - systems. Below, the analysis is described by factors that relate to our model:

Organization and process. Maturity PM methodology in the Spanish TTO, the use of the principles of project management is clearly present, evidence of the training and certificates passed by him. Nevertheless, they could not name the standard used. According to the survey, PM methodology is at an average level $(4,0)$ compared to other factors. The results of Kazakhstan are much lower $(2,1)$, due to the fact that Kazakhstan TTO haven't required the standards of PM.

Control over integration activities. The indicator of this factor is the highest of Spain - 4,7. The Kazakhstan indicator is also one of the highest among Kazakhstan factors - 3,1, after the "infrastructure" factor. It is proved that managers are confident in their work to control the integration activities of organizations. The integration process of the three areas is pronounced in the Spanish TTO than in Kazakhstan. In Kazakhstan, the situation is different: education and science realizes its innovative potential through the state.

Institualization of portfolio integration. This factor combines PM principles with the integration process. In Kazakhstan, the indicators of this factor takes the penultimate place after the project culture - 1,9. In Spain, the same situation, only the figure is much higher $-3,7$.

Resources. Financing in Spain takes place through a variety of sources: state grants, university investment in science, and the promotion of a business structure. In case of cooperation with the business sector, profit is divided between shares. What improves the survey results $-4,1$, compared with Kazakhstan - 2,8. In Kazakhstan, the profit from the innovative activities of universities, as there is no reporting on income. Firstly, Kazakhstani universities use state grants, and secondly, according to the laws of the Republic of Kazakhstan, innovative activity is exempted from taxes for three years.

Human resources. In Kazakhstan, recruitment is the usual invitation of employees to work. Only scientists choose the scope of their research. The exact way to attract businesspersons to university science hasn't been developed. The project manager himself becomes the chief scientist. In Spain, TTO and university employees are invited as other employees. However, the manager who works in the TTO between the university and the company must be from the university. For example, a university graduate who has experience in entrepreneurship, or is competent in management and marketing. 
Infrastructure. One of the highest rates in both countries among other factors is infrastructure. This explains that the survey participants are much more satisfied with the infrastructure than with other factors. According to the survey, it is clear that Kazakhstan is far behind Spanish universities in infrastructure. This is where the question of financing comes up automatically. The source of funding in Kazakhstan is mainly only the state.

Culture and ICT systems. The universities and technical and technical education integrated in the project culture, which we surveyed. They use the communication analytical tools of the PM, but they do not use the vocabulary of the PM, which can to improve the skills of project management. Communication systems are PM tools; according to the survey, Kazakhstan 2,4 and Spain 4,4 gain good points. Nevertheless, the design culture has the lowest rates Kazakhstan 1,5 and Spain 3,2. This is because project management is not widespread in both countries.

It should be conclude that the indicators of all factors in Spain and Kazakhstan are similar. However, only the indicator of developing country is much lower. However, we seen that the performance of communication systems of portfolio integration in Spain is much higher than in Kazakhstan.

Based on the obtained results, we can conclude that Kazakhstan is following the path of the Spanish experience. However, Kazakhstan can become more successful in commercializing scientific technologies and transferring knowledge and technologies. In turn, Spain can use the data from our analysis to work on barriers and improve the activities of TTOs.

\section{Conclusions}

The world is rapidly moving towards transforming itself into an economy of new knowledge. Be it the developed or developing countries, the importance of intellectual property protection has never been more evident than now. As the world moves forward in this environment, more and more of our actions are informed and shaped by how knowledge can be commercialized and can make a profit. According to the literature review, it becomes obvious that special attention is required to solve fundamentally important issues related to the analysis of the prospects for realizing the advantages of the TTOs. It is clear that TTOs have control over the process of knowledge transfer and is crucial for the application of research results. It should be noted that the problems of transfer of advanced management technologies, their implementation in practice and their significance for the host economy are getting more and more theoretical and practical understanding in the scientific literature. Based on the conducted research, the following conclusions can be drawn.
Firstly, an important area of international cooperation for developing countries is the transfer of not only the latest production technologies, but also related management technologies. It should be taken into account that in Kazakhstan there is a clear contradiction between relatively advanced production technologies that can be obtained through international exchange, and existing backward management technologies. A number of factors, but first the historically established and dominant for many decades administrative and command management system, causes this contradiction.

Secondly, the process of technology transfer is quite complex, consisting of many different types of objects (subsystems and elements). In this regard, the proposed methodology contains a complex system of characteristics indicators. In addition, the methodological basis of this research was the achievements of world and domestic economic science, other related branches of scientific knowledge, the results of scientific and practical publications and expert surveys on the development of TTO. The methodology is focused on solving the problems of quantitative analysis based on the use of primary and secondary data. The information received will allow to get complete, reliable and timely information about current processes related to the use of TTO. It should be concluded that the proposed methodological tools offer a model for organizing an integration project.

Thirdly, successful technology transfer up to the stage of product commercialization involves a constant multilevel exchange of information. Based on international differences in the integration of universities with businesses, we use the Likert scale method. We integrate the hypothesis about factors of organization and structure, resources, ICT systems and culture into a model aimed at explaining the effectiveness of TTO. Further, we decided to focuses on those countries that have not only achieved significant results in the implementation of scientific and technical achievements, but also had the opportunity to obtain reliable and formalized data.

In this study, we decided to conduct a comparative analysis of two countries - Kazakhstan and Spain. Since they had similar starting conditions at the beginning of commercialization of scientific research. It should be conclude that the indicators of all factors in Spain and Kazakhstan are similar. Based on the obtained results, we can conclude that Kazakhstan is following the path of the Spanish experience.

The process of integrating education, science and business is different in each country. The analysis shows how the integration process is going on in Spain and Kazakhstan. Each country has its advantages and disadvantages. The great advantage of Spain is that there is a real connection with business, which Kazakhstan has not yet reached. Spain 
considers it a drawback that it is not proactive, as at the beginning of the creation of the TTO, to increase the list of partners. It is important to highlighted that the reasons for mistrust, unwillingness of Kazakhstan or foreign companies to work with universities. This question may serve as a continuation of the study in the future studies.

\section{References}

Aarseth, W., Ahola, T., Aaltonen, K., Økland, A., \& Andersen, B. (2016). Project sustainability strategies: A systematic literature review. International Journal of Project Management, 35(6), 1071-1083.

Aldridge, T., \& Audretsch, D. B. (2010). Does policy influence the commercialization route? Evidence from National Institutes of Health funded scientists. Research Policy, 39(5), 583-588.

Algieri, B., Aquino, A., \& Succurro, M. (2011). Technology transfer offices and academic spin-off creation: the case of Italy. Journal of Technology Transfer, 38(4), 382-400.

Allan, L., Kistler, J., Lowe, C., Dunn, W., McGowan, C., \& Whitcher, G. (2008). Bioscience enterprise: Postgraduate education at Cambridge and Auckland. Journal of Commercial Biotechnology, 15(3), $257-271$.

Balachandra, R., \& Friar, J. (1997). Factors for Success in R\&D Projects and New Product Innovation: A Contextual Framework. Transactions on Engineering Management, 44(3), 276-287.

Baldini, N. (2010). Do royalties really foster university patenting activity? An answer from Italy. Technovation, 30(2), 109-116.

Belitski, M., Aginskaja, A., \& Marozau, R. (2019). Commercializing university research in transition economies: Technology transfer offices or direct industrial funding? Research Policy, 48(3), 601-615.

Berbegal, J., Ribeiro, D., \& Sánchez, J. (2015). Can a magic recipe foster university spin-off creation? Journal of Business Research, 68(11), 2272-2278.

Bertha, S. L. (1996). Academic research: Policies and practice. Journal of Ethno Pharmacology, 51(1-3), 59-73.

Bigliardi, B., Galati, F., Marolla G., \& Verbano, Ch. (2015). Factors affecting technology transfer offices' performance in the Italian food context. Technology Analysis \& Strategic Management, 27(4), 361-384.

Bresnen, M., Edelman, L., Newell, S., Scarbrough, H., \& Swan, J. (2003). Social practices and the management of knowledge in project environments. International Journal of Project Management, 21(3), 157-166.

Caldera, A., \& Debande, O. (2010). Performance of Spanish universities in technology transfer: An empirical analysis. Research Policy, 39(9), 1160-1173.

Chen, K., \& Kenney, M. (2007). Universities/Research Institutes and Regional Innovation Systems: The Cases of Beijing and Shenzhen. World Development, 35(6), 1056-1074.
Graff, G., Heiman, A., \& Zilberman, D. (2002). University research and offices of technology transfer. California Management Review, 45(1), 88-115.

Huang, W., Feeney, M. K., \& Welch, E. W. (2011). Organizational and individual determinants of patent production of academic scientists and engineers in the United States. Science and Public Policy, 38(6), 463-479.

Huyghe, A., \& Knockaert, M. (2015). The influence of organizational culture and climate on entrepreneurial intentions among research scientists. Journal of Technology Transfer, 40(1), 138-160.

John, A., Khan, H., Raeside, R., \& White, D. (2007). Research methods for graduate business and social science students. (1st ed.). New Delhi, India: Chaman Enterprises.

Kamara, J., Anumbab, C., \& Carrillob, P. (2002). A clever approach to selecting a knowledge management strategy. International Journal of Project Management, 20(3), 205-211.

Kireyeva, A. A., Abilkayir, N. A., \& Tsoy, A. A. (2018). A Study on the Distribution of Information and High Technology Clusters: Kazakhstan's Experience. Journal of Distribution Science, 16(4), 5-15.

Kireyeva, A. A., Lakhonin, V., \& Kalymbekova, Z. (2019). Digital Transformations to Improve the Work and Distribution of the State Scholarships Programs. Journal of Distribution Science, 7(13), 41-47.

Lawson, C. (2013) Academic patenting: the importance of industry support. Journal of Technology Transfer, 38(4), 509-535.

Lee, J. W., \& Xuan, Y. (2019). Effects of Technology and Innovation Management and Total Factor Productivity on the Economic Growth of China. Journal of Asian Finance, Economics and Business, 6(2), 63-73. https://doi.org/10.13106/jafeb.2019. vol6.no2.63

Lenfle, S. (2008). Exploration and project management. International Journal of Project Management, 26(5), 469-478.

Lindner, F., \& Wald, A. (2011). Success factors of knowledge management in temporary organizations. International Journal of Project Management, 29(7), 877-888.

Marozau, R., \& Guerrero, M. (2016). Conditioning factors of knowledge transfer and commercialization in the context of postsocialist economies: the case of Belarusian higher education institutions. International Journal of Entrepreneurship and Small Business, 27(4), 441-462.

Phillips, T., Nestor, F., Beach, G., \& Heitman, E. (2018). America COMPETES at 5 years: An Analysis of Research-Intensive Universities' RCR Training Plans. Science and Engineering Ethics, 24(9), 227-249.

Potluri, R. M., Lee, J. W., Khan, S. R., \& Vali, S. M. (2012). Challenges and Opportunities of Small Business Management and Start-Ups in India. Journal of Distribution Science, 10(7), $5-11$

Sabden, O. (2018). The concept of the future and the new paradigm of the fifth spiral: State, business, science, society 
and informatization. Journal of Asian Finance, Economics and Business, 5(4), 173-185. http://doi.org/10.13106/jafeb.2018. vol5.no4.173

Sabini, L., Muzio, D., \& Alderman, N. (2019). 25 years of 'sustainable projects'. What we know and what the literature says. International Journal of Project Management, 37(6), 820-838.

Satpayeva, Z. T., Kireyeva, A. A., Kenzhegulova, G. Zh., \& Yermekbayeva, D. Zh. (2020). Gender Equality and Women Business of Framework 5Ms in Kazakhstan: Analysis and Basic Directions. Journal of Asian Finance, Economics and Business, 7(3), 253-263. https://doi.org/10.13106/jafeb.2020. vol7.no3.253

Saunders, M., Lewis, P., \& Thornhill, A., (2009). Research methods for business students (5th ed.). Harlow, England: Pitman Publishing.
Siegel, D. S., \& Wright, M. (2007). Intellectual property: The assessment. Oxford Review Economic Policy, 23(4), 529-540.

Shakkah, S., Alaqeel, K., Alfageeh, A., \& Budiarto, R. (2016). An Investigation Study on Optimizing Enterprise Resource Planning (ERP) Implementation in Emerging Public University: Al Baha University Case Study. International Journal of Electrical and Computer Engineering, 6(4), 1920-1928.

Trilling, B., \& Ginevri, W. (2017). Project management for education: the bright to 21st century learning. (1st ed.). Project Management Institute: Educational Foundation.

Vonglao, P. (2017) Application of fuzzy logic to improve the Likert scale to measure latent variables. Kasetsart Journal of Social Sciences, 38(3), 337-344. 